\title{
PEMANFAATAN SALURAN DRAINASE SEBAGAI RUANG HIJAU TERBATAS DI KAMPUS A UNIVERSITAS NEGERI
}

\author{
Guntur Wisnu Gumelar ${ }^{1}$, Henita Rahmayanti ${ }^{2}$, Daryati $^{3}$ \\ ${ }^{1,3}$ Pendidikan Teknik Bangunan, FT, UNJ \\ ${ }^{2}$ D3 Transportasi, FT, UNJ \\ Email: ravin_wisnu@yahoo.com
}

\begin{abstract}
ABSTRAK
Penelitian dilakukan dalam upaya menjaga saluran drainase sekaligus meningkatkan RTH dan menambah estetika lingkungan. Perencanaan dilakukan pada saluran drainase terbuka di Kampus A UNJ. Perencanaan dilakukan melalui studi pustaka, mengidentifikasi ciri-ciri aspek fisik dan biologi, menganalisis potensi dan kendala yang ada di lapangan serta membuat desain dengan pendekatan retotive. Hasil penelitian didapatkan saluran drainase yang dapat dimanfaatkan sepanjang 1182,08 m. Lebar tapak yang bisa dijadikan konstruksi ruang hijau hanya $60 \mathrm{~cm}$. Tambahan RTH efektif yang diperoleh seluas 292,82 $\mathrm{m}^{2}$. Saluran drainase dibuat secara Manhole dengan ukuran $50 \mathrm{~cm} \times 60 \mathrm{~cm}$ dan $60 \times 60 \mathrm{~cm}$ yang terintegrasi dengan konstruksi ruang hijau. Jenis tumbuhan berupa bunga dan semak. Media tanam yang digunakan berupa media organik dan anorganik.
\end{abstract}

Kata Kunci: Pemanfaatan Saluran Drainase, Ruang Terbatas, Penanganan Saluran Drainase, Penambahan RTH, Kampus A UNJ.

\begin{abstract}
The research is carried out in an effort to maintain drainage channels while increasing green space and adding environmental aesthetics. Planning is carried out on open drainage channels on Campus A UNJ. Planning is done by means of literature study, identifying the characteristics of physical and biological aspects, analyzing the potential and constraints on the site and making a design with a retotive approach. The results of the study obtained drainage channels that can be utilized along $1182.08 \mathrm{~m}$. Tread width that can be used as a green space construction is only $60 \mathrm{~cm}$. The additional effective green space obtained is $292.82 \mathrm{~m}^{2}$. Drainage channels are made by Manhole with a size of $50 \mathrm{~cm} \times 60 \mathrm{~cm}$ and $60 \times 60 \mathrm{~cm}$ integrated with the construction of green spaces. Types of plants in the form of flowers and shrubs. The planting media used in the form of organic and inorganic media.
\end{abstract}

Keywords: Utilization of Drainage Channels, Limited Green Spaces, Drainage Channel Treatment, Additional Area of Green Space, Campus A UNJ. 


\section{PENDAHULUAN}

Kota Seiring bertambahnya jumlah penduduk maka semakin bertambah kebutuhan tempat tinggal dan tempat beraktivitas di suatu wilayah perkotaan dan sekitarnya yang akan mengakibatkan penggunaan lahan semakin meningkat. Kota Jakarta merupakan kota dengan perkembangan yang terpusat sehingga menyebabkan terkonsentrasinya pertumbuhan ekonomi perkotaan sehingga orientasi penduduk ke dalam kota sangat tinggi. Ledakan migrasi penduduk yang tinggi pada wilayah yang kurang akan daerah resapan seperti Jakarta adalah masalah yang signifikan dan akan menyebabkan banjir karena fasilitas drainase yang tidak memadai (Amini, 2009), ledakan migrasi tersebut menuntut kelayakan sarana dan prasarana yang memadai.

Menurut Peraturan Menteri Pekerjaan Umum Nomor 12/PRT/M/2014 Tentang Penyelenggaraan Sistem Drainase Perkotaan, drainase adalah prasarana yang berfungsi mengalirkan kelebihan air dari suatu kawasan ke badan air penerima. Sedangkan drainase perkotaan adalah drainase di wilayah kota yang berfungsi mengelola/mengendalikan air permukaan, sehingga tidak menganggu dan/atau merugikan masyarakat.Menurut Halim Hasmar $(2012 ; 1)$ drainase secara umum didefiniskan sebagai ilmu pengetahuan yang mempelajari usaha untuk mengalirkan air yang berlebihan dalam suatu konteks pemanfaatan tertentu. Menurut Gunadarma (2007:3) dalam Drainase Perkotaan merupakan sistem pengeringan dan pengaliran air dari wilayah perkotaan yang meliputi : pemukiman, kawasan industri dan perdagangan, sekolah, rumah sakit,fasilitas 5 umum lainnya, lapangan olahraga, lapangan parkir, instalasi militer, instalasi listrik dan telekomunikasi, pelabuhan udara, pelabuhan laut/sungai serta tempat lainnya yang merupakan bagian dari sarana kota. Menurut Mulyanto
(2012:10) dalam bukunya "Penataan Draianse Perkotaan" System ini direncanakan dengan kapasitas cukup untuk mengevakuasi air hujan dengan frekuensi yang direncanakan. Penentuan frekuensi di bawah ini tergantung dari kondisi lokal setempat dan pada keyakinan perencanannya tetapi juga dipertimbangkan biaya pembuatan sistem drainase

Di sisi lain Kota jakarta merupakan kota yang sering dilanda banjir. Kawasan rawan banjir dan genangan di Kota Jakarta secara geografis telah diidentifikasi sebagai lokasi yang sangat rawan terjadi banjir dan genangan air. Kondisi diatas diperburuk oleh pesatnya alih fungsi lahan yang ada akibat pertambahan penduduk yang pesat. Sementara itu arus pembangunan yang ada tidak berorientasi kepada lingkuangan. Sebagai contoh, dengan tingkat pembangunan yang tiap tahunnya mencapai 20,2\% (Bappeda DKI Jakarta,2012), tidak semua drainase yang ada berfungsi dengan baik. Ruang terbuka hijau di Jakarta hanya seluas $9,8 \%$.

Kondisi drainase di DKI Jakarta banyak yang tidak berfungsi dengan baik. Banyak sekali ditemukan drainase yang terbengkalai karena tidak dirawat, kotor, mengeluarkan bau tidak sedap dan merusak pemandangan. Hal ini bisa mengakibatkan banjir saat musim penghujan dan sumber penyakit bagi masyarakat yang tinggal disekitarnya. Seperti yang dilansir dari media unjkita.com, pada hari Kamis tanggal 8 Desember 2016 terjadi banjir di kampus A UNJ “...Dari sekian titik genangan, jalanan depan Pustikom menjadi yang terparah genangan airnya menurut pantauan wartawan unjkita. Menurut pantauan redaksi, tinggi genangan air pada titik ini bahkan mencapai betis orang dewasa. Dan genangan air sudah hampir memasuki area dalam gedung yang lebih tinggi dari jalanan. Selain itu pada hari Kamis tanggal 15 febuari 2018 diliput oleh Sigma TV UNJ bahwa ketinggian banjir di beberapa titik mencapai lutut orang dewasa. 
Analisis hidrologi tidak hanya diperlukan dalam perencanaan berbagai bangunan air seperti : bendungan, bangunan pengendali banjir, dan bangunan irigasi, tetapi juga diperlukan untuk bangunan jalan raya, lapangan terbang, dan bangunan lainnya. (Soemarto,1987) Menurut Subarkah (1980), Analisa hidrologi memiliki peranan yang penting dalam melakukan perencanaan bangunan air dalam bidang pengairan, baik unruk perencanaan isrigasi maupun dalam perencanaan saluran drainase.

Sering kita jumpai saluran drainase yang di dalamnya terdapat banyak sampah organik maupun sampah an-organik serta lumpur yang cukup tebal mengendap pada dasar saluran drainase tersebut. Sampah anorganik berasal dari aktifitas warga yang kurang kesadaran untuk membuang sampah pada tempat sampah dan kebiasaan kebanyakan warga membuang sampah sembarangan termasuk ke dalam saluran drainase. Di musim hujan sampah tersebut menyumbat air yang mengalir di saluran drainase dan sering menyebabkan terjadinya banjir. Oleh karena itu untuk mengurangi dampak dari polusi yang terjadi dan juga untuk mengurangi faktor penyebab banjir pada Kampus A diperlukan solusi terkait permasalahan yang ada dengan pembuatan ruang hijau terbatas dengan memanfaatkan lahan saluran drainase.

\section{METODE}

Penelitian ini dilaksanakan di Kampus A Universias Negeri Jakarta, dimulai dari bulan Oktober hingga Desember 2017. Data yang dikumpulkan terdiri dari data primer dan data sekunder. Dimana data primer diperoleh dari hasil survei lapangan dan mengurus perizinan untuk mendapatkan data yang dibutuhkan kepada pihak terkait. Sementara data sekunder yang diperlukan diperoleh melalui studi pustaka. Pengumpulan data dilakukan sebelum terjun ke lapangan dengan menggunakan peta dasar sebagai acuan, seperti peta fisik dan biofisik yang mencakup peta lokasi dan peta drainase.

Selanjutnya, di tahap perancangan, terlebih dahulu melakukan perumusan konsep untuk kemudian membuat rancangan lanskap dan detail gambar agar desain lanskap lebih mudah dimengerti.

\section{HASIL DAN PEMBAHASAN}

Tapak penelitian adalah saluran drainase sekunder terbuka yang terletak di jalan Rawamangun Muka, RT.11/RW.14, kelurahan Rawamangun, kecamatan Pulo Gadung, Kota Jakarta Timur. Kondisi saluran drainase terbuka yang diteliti merupakan ruangan terbuka namun di beberapa bagian tertutup oleh aspal dan beton yang berfungsi sebagai jalan kendaraan dan pejalan kaki.

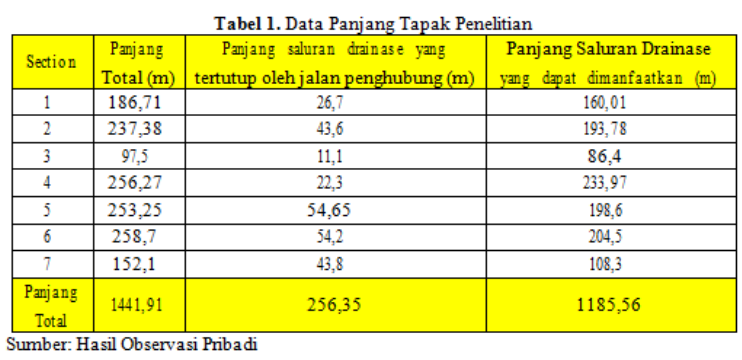

Dari tabel tersebut dapat diketahui bahwa ruang pada saluran drainase yang dapat dimanfaatkan cukup panjang yaitu sepanjang $1.185,56 \mathrm{~m}$. Hal ini tentunya cukup baik apabila ruang tersebut dapat dimaksimalkan untuk ruang hijau terbatas.

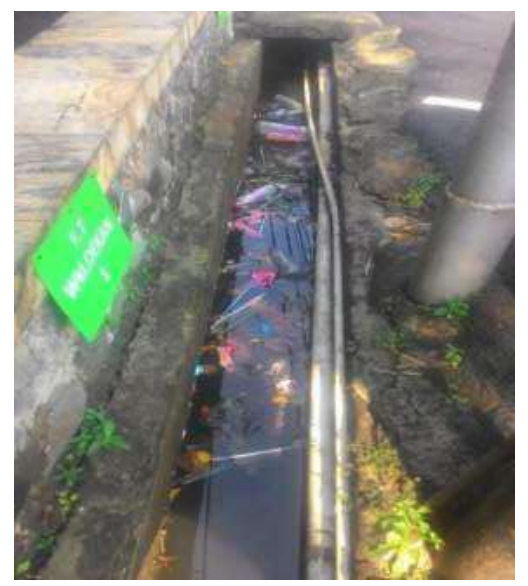


Gambar 1. Kondisi saluran drainase terbuka UNJ di Jalan Daksninapati Utara

Dari gambar tersebut terlihat pada saluran drainase terbuka Kampus A UNJ terdapat banyak sampah, baik organik maupun an organik. Pada gambar sebelah kiri menunjukan bahwa aliran air membuat sampah mengambang dan hanyut mengikuti arah aliran air.

Konsep perencanaan dengan sistem retrofit membuat pilihan dalam memilih konstruksi ruang hijau terbatas dan jenis tanaman sangat bergantung pada kondisi dari saluran drainase yang tersedia. Perencanaan konstruksi ruang hijau harus menyesuaikan dengan ruang yang dapat dimanfaatkan agar tidak mengganggu ruang lainnya seperti ruang parkir kendaraan dan trotoar di lingkungan Kampus A UNJ. Oleh sebab itu perencanaan dilakukan dengan desain minimalis dengan memaksimalkan fungsi dari tanaman pada ruang yang terbatas dengan berfokus pada fungsinya sebagai pembersih udara dan penghias lingkungan. Dimensi, bentuk dan konstruksi ruang hijau terbatas dapat didesain setelah observasi dan analisis terkait saluran drainase Kampus A UNJ dilakukan. Berikut merupakan desain ruang hijau terbatas 1 .

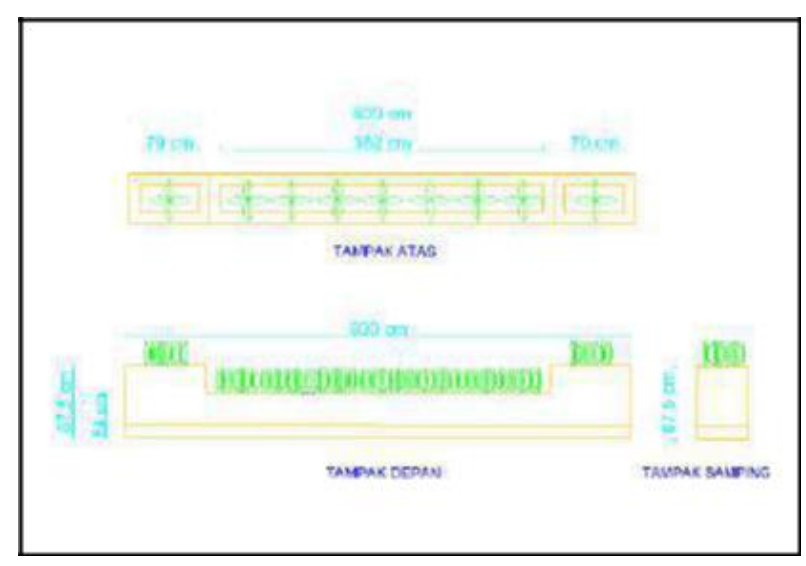

Gambar 2. Desain Gambar Ruang Hijau Terbatas

Untuk luasan tambahan ruang hijau dari pemanfaatan ruang saluran drainase penulis melakukan perhitungan luasan dan hasil yang didapatkan adalah luasan ruang hijau bertambah seluas $292,82 \mathrm{~m}^{2}$. Hasil ini merupakan hasil maskimal yang didapat dari pemanfaatan ruang terbatas pada saluran drainase untuk dijadikan ruang hijau. Dimana lebar untuk konstruksi ruang hijau yang bisa dipakai hanya $60 \mathrm{~cm}$, hal ini disebabkan oleh ruang di sekitar tapak penelitian yang tidak memungkinkan untuk digunakan karena merupakan jalan dan tempat parkir mobil. Untuk gambar desain ruang hijau dapat dilihat pada lampiran 4 hal $68-73$.

Kemudian untuk pembuangan air pada konstruksi ruang hijau, dipasang pipa pvc berukuran $1 / 2$ " (inchi). Pipa diletakan pada dasar media tanam dan ditaruh pada lapisan spesi, pipa dibuat menembus lapisan bata. Untuk dapat mengalirkan air keluar pipa diberikan kemiringan sebesar $2^{\circ}$ dan diberikan jaring tipis atau kain tipis untuk mencegah terbawanya media tanam oleh aliran air

Untuk ruang vegetasi pada desain ruang hijau ini menyesuaikan dengan ruang yang tersisa dari konstruksinya. Ruang vegetasi merupakan bagian tapak yang akan ditanami oleh tanaman hias. Luasan ruang ini bergantung pada bagian tapak yang tersisa. Pemanfaatan ruang tersisa tersebut sejalan dengan konsep retrofit (Townshend dan Gingerberd,2010 ). Ruang vegetasi berbentuk persegi panjang dengan elevasi yang berbeda. Dimensi ruang vegetasi 1 ini seluas $34 \mathrm{~cm}$ x $522 \mathrm{~cm}$. Sementara itu untuk memperindah lingkungan Kampus A UNJ di malam hari, pada konstruksi ruang hijau dipasang lampu taman guna mendukung aktifitas warga kampus A pada malam hari.

\section{(4) KESIMPULAN}

Berdasarkan hasil pemanfaatan saluran drainase sebagai ruang hijau terbatas di Kampus A UNJ dapat disimpulkan hasil sebagai berikut:

1) Pemanfaatan Saluran Drainase Sebagai Ruang Hijau Terbatas, Dapat bermanfaat yaitu dengan bertambahnya luasan ruang hijau sebesar 292,82 $\mathrm{m}^{2}$. Tambahan luas ruang hijau ini cukup signifikan mengingat lahan yang digunakan merupakan lahan 
Pemanfaatan Saluran Drainase... (Guntur/ hal. 6-9)

terbatas yang kurang dimanfaatkan, selain itu juga berpotensi

memberikan dampak negatif kepada lingkungan dan warga Kampus A UNJ

yang beraktifitas. Dengan teraplikasikannya penelitian ini dapat merubah potensi dampak negatif menjadi potensi dampak positif bagi lingkungan dan warga Kampus A UNJ.

2) Pemanfaatan ruang hijau terbatas di Kampus A UNJ diterapkan dengan man hole dan jaring kawat. Desain tersebut diterapkan guna mengintegrasikan antara ruang hijau terbatas dengan sistem maintenance saluran drainase. Konsep ini bertujuan untuk memberikan kemudahan petugas maintenance dalam melakukan perawatan dan pembersihan saluran drainase. Selain itu konsep ini juga

bertujuan untuk mencegah atau meminimalisir sampah masuk ke dalam saluran drainase.

3) Tanaman yang diterapkan pada desain ini terdiri dari tanaman hias yang memiliki banyak manfaat. Tanaman Sanseveira yang ditanam sepanjang tapak berfungsi sebagai sabuk tanaman pembersih udara dari polutan. Tanaman Lidah Buaya dapat dimanfaatkan sebagai bahan praktek di bidang kecantikan. Tanaman hias lainnya berfungsi sebagai penambah nilai estetika lingkungan.

\section{REFERENSI}

Amini, M., dan Akbari, H. 2014. Studying Effect Of Site Quality On Online Repurchase Intention Through Satisfaction, Trust And Commitment Of Customer. Indian Journal of Fundamental and Applied Life Sciences, Vol. 4, No. 4, pp. 2839-2849.

[BAPPEDA] Badan Perencanaan dan Pembangunan DKI Jakarta tahun 2012

Badudu, J. S. 2018. Kamus Besar Bahasa Indonesia Online. (https://Kbbi.web.id). Berkelanjutan, Andi Offsett, Yogyakarta.

Gelbert M, Prihanto D, Suprihatin A. (1996). Konsep Pendidikan Linkungan Hidup dan "Wall Chart". Buku Panduan
Pendidikan Lingkungan Hidup, PPPGT/VEDC, Malang.

Pickard, B.R, Daniel, J, Maheffey, M, Jackson, L.E. \& Neale, A. (2015). Enviro Atlas: A New Geospatial Tool to Foster Ecosystem Service Science and Resource Management. Ecosystem Service.

Republik Indonesia. 2012. Peraturan

Gubernur No. 38 Tahun 2012. Jakarta.

Soemarto, C.D, 1995. Hidrologi Teknik. Erlangga. Jakarta

Subarkah, Imam. (1980). Hidrologi untuk Perencanaan Bangunan Air. Idea Dharma. Bandung.

Suripin, (2004). Drainase Perkotaan yang Townsend, MC. (2010). Diagnosis Keperawatan Psikiatri Rencana Asuhan \& Medikasi Psikotropik. Jakarta : EGC 